\title{
Formation of interstellar propanal and 1-propanol ice: a pathway involving solid-state $\mathrm{CO}$ hydrogenation
}

\author{
D. Qasim ${ }^{1}$, G. Fedoseev ${ }^{2}$, K.-J. Chuang ${ }^{1,3, \star}$, V. Taquet ${ }^{4}$, T. Lamberts ${ }^{5}$, J. He$^{1}$, S. Ioppolo ${ }^{6}$, \\ E. F. van Dishoeck ${ }^{3}$, and H. Linnartz ${ }^{1}$
}

\author{
${ }^{1}$ Sackler Laboratory for Astrophysics, Leiden Observatory, Leiden University, PO Box 9513, 2300 RA Leiden, The Netherlands \\ e-mail: dqasim@strw. leidenuniv.nl \\ 2 INAF - Osservatorio Astrofisico di Catania, via Santa Sofia 78, 95123 Catania, Italy \\ ${ }^{3}$ Leiden Observatory, Leiden University, PO Box 9513, 2300 RA Leiden, The Netherlands \\ ${ }^{4}$ INAF - Osservatorio Astrofisico di Arcetri, Largo E. Fermi 5, 50125 Florence, Italy \\ ${ }^{5}$ Leiden Institute of Chemistry, Leiden University, PO Box 9502, 2300 RA Leiden, The Netherlands \\ ${ }^{6}$ School of Electronic Engineering and Computer Science, Queen Mary University of London, Mile End Road, \\ London E1 4NS, UK
}

Received 6 February 2019 / Accepted 19 May 2019

\begin{abstract}
Context. 1-propanol $\left(\mathrm{CH}_{3} \mathrm{CH}_{2} \mathrm{CH}_{2} \mathrm{OH}\right)$ is a three carbon-bearing representative of the primary linear alcohols that may have its origin in the cold dark cores in interstellar space. To test this, we investigated in the laboratory whether 1-propanol ice can be formed along pathways possibly relevant to the prestellar core phase.

Aims. We aim to show in a two-step approach that 1-propanol can be formed through reaction steps that are expected to take place during the heavy $\mathrm{CO}$ freeze-out stage by adding $\mathrm{C}_{2} \mathrm{H}_{2}$ into the $\mathrm{CO}+\mathrm{H}$ hydrogenation network via the formation of propanal $\left(\mathrm{CH}_{3} \mathrm{CH}_{2} \mathrm{CHO}\right)$ as an intermediate and its subsequent hydrogenation.

Methods. Temperature programmed desorption-quadrupole mass spectrometry (TPD-QMS) was used to identify the newly formed propanal and 1-propanol. Reflection absorption infrared spectroscopy (RAIRS) was used as a complementary diagnostic tool. The mechanisms that can contribute to the formation of solid-state propanal and 1-propanol, as well as other organic compounds, during the heavy CO freeze-out stage are constrained by both laboratory experiments and theoretical calculations.

Results. Here it is shown that recombination of HCO radicals formed upon $\mathrm{CO}$ hydrogenation with radicals formed via $\mathrm{C}_{2} \mathrm{H}_{2}$ processing $-\mathrm{H}_{2} \mathrm{CCH}$ and $\mathrm{H}_{3} \mathrm{CCH}_{2}$ - offers possible reaction pathways to solid-state propanal and 1-propanol formation. This extends the already important role of the $\mathrm{CO}$ hydrogenation chain to the formation of larger complex organic molecules. The results are compared with ALMA observations. The resulting 1-propanol:propanal ratio concludes an upper limit of $<0.35-0.55$, which is complemented by computationally derived activation barriers in addition to the experimental results.
\end{abstract}

Key words. astrochemistry - astrobiology - methods: laboratory: solid state - ISM: molecules - ISM: clouds - ISM: abundances

\section{Introduction}

The search for three carbon-bearing aldehydes and alcohols has been the subject of a number of devoted observational studies. An example of recent observations of such species is the work by Lykke et al. (2017), where propanal (an aldehyde), among other organics, was detected towards the low-mass protostar IRAS 16293-2422B. In addition to these observations, propanal has also been identified in the Sagittarius B2 North (Sgr B2(N)) molecular cloud (Hollis et al. 2004; McGuire et al. 2016) and within the Central Molecular Zone of the Milky Way (RequenaTorres et al. 2008). Its detection on comet 67P/ChuryumovGerasimenko was claimed by Goesmann et al. (2015) but is still under debate (Altwegg et al. 2017). Given the chemical link between aldehydes and alcohols, it is expected that propanol will be formed alongside propanal. Yet in comparison to propanal, the number of reported detections of 1-propanol in observational projects is very limited. Observations towards Sgr B2(N2), the

^ Current address: Laboratory Astrophysics Group of the Max Planck Institute for Astronomy at the Friedrich Schiller University Jena, Institute of Solid State Physics, Helmholtzweg 3, 07743 Jena, Germany. northern hot molecular core within Sgr B2(N), only lead to an upper limit value of $<2.6 \times 10^{17} \mathrm{~cm}^{-2}$ for 1-propanol (Müller et al. 2016). Tercero et al. (2015) discussed the identification of 1-propanol towards Orion KL, but their claim has been questioned by others (Müller et al. 2016). The detection of propanol (without isomeric details) on comet 67P/ChuryumovGerasimenko was reported by Altwegg et al. (2017).

In the laboratory, both propanal and propanol have been synthesized in astrophysical ice analogue experiments that require "energetic" processing for product formation. "Energetic" refers here to a radical-induced process that requires the involvement of UV, cosmic rays, and/or other "energetic" particles. Kaiser et al. (2014) and Abplanalp et al. (2016) showed that propanal can be formed by the electron-induced radiation of $\mathrm{CO}: \mathrm{CH}_{4}$ or $\mathrm{CO}: \mathrm{C}_{2} \mathrm{H}_{6}$. Hudson et al. (2017) were able to form propanal by proton irradiation of a $\mathrm{CO}_{2}: \mathrm{C}_{3} \mathrm{H}_{6}$ ice mixture at $10 \mathrm{~K} . \mathrm{H}_{2} \mathrm{O}:{ }^{13} \mathrm{CH}_{3} \mathrm{OH}: \mathrm{NH}_{3} 78 \mathrm{~K}$ ice exposed to UV photons and heated to room temperature also yielded propanal (de Marcellus et al. 2015). Propanol was reported to be formed by electron irradiation of a ${ }^{13} \mathrm{CO}:{ }^{13} \mathrm{CD}_{4}$ ice mixture at $5 \mathrm{~K}$ in experiments that did not allow to discriminate between 1- and 2-propanol (Abplanalp et al. 2018a). 
In both the laboratory and observational work, propanal has been detected in conjunction with other organics such as acetone, propylene oxide, acetaldehyde, and so on. This demonstrates that propanal may be a reaction product in a number of astrochemical formation networks and its presence in the ISM may therefore be linked to the formation of a range of organic species. In this article, we focus solely on the formation of propanal and its direct derivative, 1-propanol, focusing on pathways relevant to the prestellar core, that is low temperature of $\sim 10 \mathrm{~K}$ and predominantly "non-energetic" processing. "Non-energetic" is used to refer to radical-induced processes that do not involve external energy input such as UV, cosmic rays, and/or electrons.

The particular focus on 1-propanol is strongly motivated by the astrobiological relevance of this compound. 1-propanol is a primary alcohol, and it is hypothesized that primary alcohols may have been the constituents of cell membranes during abiogenesis. Cell membranes are currently and commonly composed of glycerophospholipids (Moran et al. 2012), but whether such complex amphiphiles could be available on the early Earth is debated (Deamer et al. 2002). More simple and thus more likely lipids would be those composed of primary alcohols, such as prenol lipids. Additionally, the cell membranes of archaea (i.e., domain of ancient prokaryotic unicellular organisms) are known to be composed of primary alcohols (De Rosa et al. 1986), providing extra motivation to investigate formation routes of primary alcohols, including propanol.

In this study we investigate whether propanal and 1-propanol can be formed by adding acetylene $\left(\mathrm{C}_{2} \mathrm{H}_{2}\right)$ to the $\mathrm{CO}+\mathrm{H}$ surface reaction chain. That is, we focus on the "non-energetic" (dense cloud relevant) processing of the ice. It has been experimentally demonstrated that complex organic molecules (COMs) as large as glycerol (a polyol compound) and/or glyceraldehyde (an aldose) - can be formed below $20 \mathrm{~K}$ and without "energetic" input via the solid-state CO hydrogenation network (Fedoseev et al. 2015, 2017; Butscher et al. 2015, 2017; Chuang et al. 2016). This aligns with the observationally constrained heavy CO freeze-out stage (Pontoppidan 2006; Boogert et al. 2015; Qasim et al. 2018). It has been shown that the $\mathrm{CO}+\mathrm{H}$ reaction product, formaldehyde $\left(\mathrm{H}_{2} \mathrm{CO}\right)$, can be hydrogenated to form methanol $\left(\mathrm{CH}_{3} \mathrm{OH}\right.$; Watanabe \& Kouchi 2002; Fuchs et al. 2009). In a somewhat related way, glycolaldehyde $\left(\mathrm{HCOCH}_{2} \mathrm{OH}\right)$ and ethylene glycol $\left(\mathrm{H}_{2} \mathrm{COHCH}_{2} \mathrm{OH}\right)$ are proposed to be linked through sequential $\mathrm{H}$-addition reactions (Fedoseev et al. 2017). Additionally, acetaldehyde $\left(\mathrm{CH}_{3} \mathrm{CHO}\right)$ can be hydrogenated to form ethanol $\left(\mathrm{CH}_{3} \mathrm{CH}_{2} \mathrm{OH}\right.$; Bisschop et al. 2007). Thus we expect propanal to be hydrogenated to form 1-propanol.

The hydrogenation of $\mathrm{C}_{2} \mathrm{H}_{2}$ has a barrier (Kobayashi et al. 2017) and it is expected that in space, hydrocarbon radicals formed by atom-addition are good candidates to combine with reactive $\mathrm{CO}+\mathrm{H}$ intermediates to form COMs. For these reasons, in this study, the $\mathrm{CO}$ and $\mathrm{C}_{2} \mathrm{H}_{2}$ solid-state hydrogenation chains are connected to investigate the formation of reaction products that cannot be formed along the individual hydrogenation schemes. It should be noted that $\mathrm{C}_{2} \mathrm{H}_{2}$ has not yet been observed in interstellar ices. In the experiments discussed below, $\mathrm{C}_{2} \mathrm{H}_{2}$ was used both as a likely interstellar precursor species, and as a tool to form hydrocarbon radicals, in a comparable way to how $\mathrm{O}_{2}$ was used to generate $\mathrm{OH}$ radicals (Cuppen et al. 2010).

This paper is organised in the following way. Section 2 is an overview of the experimental setup and performed experiments. Section 3 contains results that show how propanal and possibly 1-propanol are formed by the simultaneous hydrogenation of $\mathrm{CO}$ and $\mathrm{C}_{2} \mathrm{H}_{2}$, and how propanal hydrogenation unambiguously results in the formation of 1-propanol. In Sect. 4, we discuss the identification and formation pathways of a variety of organic compounds. Section 5 is a discussion on how this combined laboratory work and theoretical calculations connect to the chemical inventory during the heavy $\mathrm{CO}$ freeze-out stage, and compares the outcomes with recent observations from the Atacama Large Millimeter/submillimeter Array (ALMA). Section 6 is a summary of the findings presented in this paper.

\section{Experimental procedure}

\subsection{Description of the setup}

All experiments described in this study took place in the ultrahigh vacuum (UHV) setup, SURFRESIDE ${ }^{2}$. The design of the setup is described by Ioppolo et al. (2013), and details on the recent modifications are given by Fedoseev et al. (2017), Chuang et al. (2018), and Qasim et al. (2018). Below, only the relevant settings are summarised. Ices were formed on a gold-plated copper substrate that is positioned in the centre of the main chamber (base pressure of low $\sim 10^{-10}$ mbar range) and can be cooled to $7 \mathrm{~K}$ by a closed-cycle helium cryostat and heated to $450 \mathrm{~K}$ by resistive heating. Substrate temperatures were measured by a silicon diode sensor with a $0.5 \mathrm{~K}$ absolute accuracy.

Connected to the central vacuum chamber are two atomic beam lines. Hydrogenation of the ice was possible by a hydrogen atom beam source (HABS; Tschersich \& Von Bonin 1998; Tschersich 2000; Tschersich et al. 2008). H-atoms were formed by the thermal cracking of hydrogen molecules $\left(\mathrm{H}_{2}\right.$; Linde 5.0) within the HABS chamber. As the atoms and undissociated $\mathrm{H}_{2}$ molecules exited the HABS chamber, they were collisionally cooled by a nose-shaped quartz pipe before landing on the icy substrate, where they were thermalized instantly to the temperature of the substrate. The second atomic beam line, a microwave plasma atom source, was not used in the present study.

Gases and vapours were prepared as follows. Acetylene (5\% of $\mathrm{C}_{2} \mathrm{H}_{2}$ in $\mathrm{He}$; Linde 2.6) and carbon monoxide (CO; Linde 4.7) entered the main chamber via two separate pre-pumped dosing lines equipped with two leak valves. ${ }^{13} \mathrm{CO}$ (Sigma-Aldrich $99 \%$ ) and ${ }^{13} \mathrm{C}^{18} \mathrm{O}$ (Sigma-Aldrich 99\%) isotopologues were used as tools to confirm the identification of the formed products. Propanal (Sigma-Aldrich $\geq 98 \%$ ) and 1-propanol (Honeywell $\geq$ 99.9\%) solutions, which were placed in individual glass tubes connected to the gas manifold by ultra-torr fittings, underwent freeze-pump-thaw cycles in order to remove gas impurities and were subsequently bled into the main chamber through the aforementioned dosing lines.

Two complementary diagnostic tools were used to monitor ice processing. Reflection absorption infrared spectroscopy (RAIRS) simultaneously samples the consumption of precursor material and the formation of reaction products by visualizing the intensity decrease or increase, respectively, of molecule specific vibrational modes. In our setup, a Fourier Transform Infrared Spectrometer (FTIR) was used to cover the 4000$750 \mathrm{~cm}^{-1}$ region with a spectral resolution of $1 \mathrm{~cm}^{-1}$. In total, 512 scans were averaged over $230 \mathrm{~s}$ to obtain one spectrum. Temperature programmed desorption-quadrupole mass spectrometry (TPD-QMS) was used to investigate the thermally desorbed ice constituents as a function of desorption temperature. A typical ramp rate of $5 \mathrm{~K} \mathrm{~min}^{-1}$ was applied. The QMS electron impact source was operated at $70 \mathrm{eV}$, which induces well characterised and molecule specific fragment patterns. RAIRS is less sensitive than TPD-QMS, but has the advantage that it does not destroy the ice. The latter probes two moleculespecific parameters: the desorption temperature and the electron 
Table 1. Selected experiments and experimental conditions.

\begin{tabular}{lccccccccc}
\hline \hline No. & Experiments & $\begin{array}{c}\text { Ratio } \\
\mathrm{C}_{2} \mathrm{H}_{2}: \mathrm{CO}: \mathrm{H}\end{array}$ & $\begin{array}{c}T_{\text {sample }} \mathrm{K} \\
\mathrm{Cm}^{-2} \mathrm{~s}^{-1}\end{array}$ & $\begin{array}{c}\text { Flux }_{\mathrm{C}_{2} \mathrm{H}_{2}} \\
\mathrm{~cm}^{-2} \mathrm{~s}^{-1}\end{array}$ & $\begin{array}{c}\text { Flux } \\
\mathrm{cm}^{-2} \mathrm{~s}^{-1}\end{array}$ & $\begin{array}{c}\text { Flux }_{\text {propanal }} \\
\mathrm{cm}^{-2} \mathrm{~s}^{-1}\end{array}$ & $\begin{array}{c}\text { Flux } \\
\mathrm{cm}^{-2} \mathrm{~s}^{-1}\end{array}$ & $\begin{array}{c}\text { Time } \\
\mathrm{s}\end{array}$ \\
\hline 1.0 & $\mathrm{C}_{2} \mathrm{H}_{2}+\mathrm{CO}+\mathrm{H}$ & $1: 2: 10$ & 10 & $5 \times 10^{11}$ & $1 \times 10^{12}$ & $5 \times 10^{12}$ & - & - & 21600 \\
1.1 & $\mathrm{C}_{2} \mathrm{H}_{2}+\mathrm{CO}$ & - & 10 & $5 \times 10^{11}$ & $1 \times 10^{12}$ & - & - & - & 21600 \\
1.2 & $\mathrm{C}_{2} \mathrm{H}_{2}+\mathrm{H}$ & - & 10 & $5 \times 10^{11}$ & - & $5 \times 10^{12}$ & - & - & 21600 \\
1.3 & $\mathrm{C}_{2} \mathrm{H}_{2}+\mathrm{C}^{18} \mathrm{O}+\mathrm{H}$ & $1: 2: 10$ & 10 & $5 \times 10^{11}$ & $1 \times 10^{12}$ & $5 \times 10^{12}$ & - & - & 21600 \\
1.4 & $\mathrm{C}_{2} \mathrm{H}_{2}+{ }^{13} \mathrm{C}^{18} \mathrm{O}+\mathrm{H}$ & $1: 2: 10$ & 10 & $5 \times 10^{11}$ & $1 \times 10^{12}$ & $5 \times 10^{12}$ & - & - & 21600 \\
2.0 & $1-$ propanol & - & 10 & - & - & - & - & $1 \times 10^{12}$ & 3600 \\
2.1 & Propanal + H & - & 10 & - & - & $5 \times 10^{12}$ & $3 \times 10^{12}$ & - & 28800 \\
2.2 & Propanal + H & - & 10 & - & - & $5 \times 10^{12}$ & $2 \times 10^{11}$ & - & 7200 \\
2.3 & Propanal & - & 10 & - & - & - & $2 \times 10^{12}$ & - & 3600 \\
2.4 & Propanal & - & 10 & - & - & - & $3 \times 10^{14}$ & - & 100 \\
\hline
\end{tabular}

Notes. Molecular fluxes were determined by the Hertz-Knudsen equation.

impact induced fragmentation pattern. In general, this combination allows unambiguous molecule identifications, particularly when isotopic species are also used as a cross-check. For an overview of the positives and negatives of both methods, see the work by Ioppolo (2014).

\subsection{Overview of experiments}

Table 1 lists the experiments that were performed in this study. All fluxes were determined via the Hertz-Knudsen equation (Kolasinski 2012) except for the H-atom flux, which was based on an absolute D-atom flux measured by Ioppolo et al. (2013). The purpose of the experiments is described below.

Experiments 1.0-1.4 were used to verify the formation of propanal by the radical-radical recombination reaction between the radicals formed from hydrogenation of $\mathrm{CO}$ and $\mathrm{C}_{2} \mathrm{H}_{2}$. Experiment 1.0 was compared to experiments 1.1 and 1.2 to demonstrate that product formation requires radical species to be formed in the ice. We note that the listed $\mathrm{C}_{2} \mathrm{H}_{2}: \mathrm{CO}: \mathrm{H}$ ratio in Table 1 was experimentally found to be the most favourable ratio for product formation among our set of performed ratios (not discussed here). Carbon monoxide (CO) isotopologues were exploited in experiments 1.3 and 1.4 to witness the mass-tocharge $(\mathrm{m} / \mathrm{z})$ shift in the TPD experiments that must occur if propanal (and 1-propanol) is formed.

Experiments 2.0-2.4 were used to verify the formation of 1-propanol ice via the surface hydrogenation of propanal at $10 \mathrm{~K}$. Experiment 2.0 provides a 1-propanol reference. The TPD spectra of experiments $2.0,2.2$, and 2.3 were analysed to verify 1-propanol formation. Experiments 2.3 and 2.4 were used as controls to verify that the IR feature at $969 \mathrm{~cm}^{-1}$ in experiment 2.1 does not overlap with the features of propanal. The feature was additionally compared to the IR spectrum of experiment 2.0 .

It should be noted that in all experiments, the precursor species listed in Table 1 were used in co-deposition experiments. These result in a higher product abundance compared to experiments in which pre-deposited precursor species are bombarded. Moreover, co-deposition is more representative for the actual processes taking place in space (Linnartz et al. 2015).

\section{Results}

\subsection{Formation of propanal from $\mathrm{C}_{2} \mathrm{H}_{2}: \mathrm{CO}$ hydrogenation}

Figure 1 shows the RAIR spectrum obtained after the codeposition of $\mathrm{C}_{2} \mathrm{H}_{2}+\mathrm{CO}+\mathrm{H}$ at $10 \mathrm{~K}$. A list of the identified
RAIR bands for this experiment is found in Table 2. The solid-state hydrogenation of an ice containing $\mathrm{C}_{2} \mathrm{H}_{2}$ leads to the formation of $\mathrm{C}_{2} \mathrm{H}_{4}$ and $\mathrm{C}_{2} \mathrm{H}_{6}$, which was also reported by Kobayashi et al. (2017). The reaction of $\mathrm{CO}$ and $\mathrm{H}$, which has been extensively investigated by Watanabe \& Kouchi (2002) and Fuchs et al. (2009), yields $\mathrm{H}_{2} \mathrm{CO}$ and $\mathrm{CH}_{3} \mathrm{OH}$. There is no clear spectral proof of propanal or 1-propanol.

Besides the resulting RAIR spectrum of $\mathrm{C}_{2} \mathrm{H}_{2}+\mathrm{CO}+\mathrm{H}$ in Fig. 1, also RAIR spectra of several control experiments are shown. The $\mathrm{C}_{2} \mathrm{H}_{2}+\mathrm{CO}$ RAIR spectrum shows two features that belong to $\mathrm{C}_{2} \mathrm{H}_{2}$ and $\mathrm{CO}$, but does not show the signatures of the other $\mathrm{CH}$ - and $\mathrm{HCO}$-bearing species that are seen in the RAIR spectrum when $\mathrm{H}$ is present. As expected, this implies that $\mathrm{H}$-atoms, and subsequently radicals, are required for the formation of $\mathrm{C}_{2} \mathrm{H}_{4}, \mathrm{C}_{2} \mathrm{H}_{6}, \mathrm{H}_{2} \mathrm{CO}$, and $\mathrm{CH}_{3} \mathrm{OH}$ in the $\mathrm{C}_{2} \mathrm{H}_{2}+\mathrm{CO}+$ $\mathrm{H}$ experiment. Some of the spectra of these reaction products are shown in Fig. 1 to point out their IR features in the $\mathrm{C}_{2} \mathrm{H}_{2}+$ $\mathrm{CO}+\mathrm{H}$ experiment. The RAIR spectra of pure propanal and 1-propanol in Fig. 1 illustrate the obstacle of detecting these species as reaction products in the RAIRS data of the $\mathrm{C}_{2} \mathrm{H}_{2}+$ $\mathrm{CO}+\mathrm{H}$ experiment. The strongest band of propanal overlaps with the feature of $\mathrm{H}_{2} \mathrm{CO}\left(\sim 1750 \mathrm{~cm}^{-1}\right)$, whereas the strongest bands of 1-propanol overlap with the features of $\mathrm{C}_{2} \mathrm{H}_{4}(\sim 950$ and $\left.\sim 2950 \mathrm{~cm}^{-1}\right), \mathrm{C}_{2} \mathrm{H}_{6}\left(\sim 2950 \mathrm{~cm}^{-1}\right)$, and $\mathrm{CH}_{3} \mathrm{OH}\left(\sim 1050 \mathrm{~cm}^{-1}\right)$, as shown in Fig. 1 by the dashed and dotted lines. With such closely overlapping features, even the incorporation of propanal and 1-propanol in a matrix containing relevant reactant species, which would affect the peak positions and profiles, would likely not lead to the explicit detection of propanal and 1-propanol IR signatures. Due to the lack of distinguishable IR peaks of propanal and 1-propanol in the $\mathrm{C}_{2} \mathrm{H}_{2}+\mathrm{CO}+\mathrm{H}$ spectrum, it is necessary to resort to an alternative detection method, such as TPD.

TPD spectra along with the QMS cracking pattern of synthesized and deposited propanal are compared in Fig. 2. In the TPD spectra obtained after the co-deposition of $\mathrm{C}_{2} \mathrm{H}_{2}+\mathrm{CO}+$ $\mathrm{H}$ (top left), the $\mathrm{m} / \mathrm{z}$ signals of 58 and 57 peak at $125 \mathrm{~K}$, which is what is observed in the TPD spectra of a pure propanal ice (bottom left). We note that there is a shoulder around $115 \mathrm{~K}$ in the pure propanal experiment that is not observed in the $\mathrm{C}_{2} \mathrm{H}_{2}+$ $\mathrm{CO}+\mathrm{H}$ experiment. This is believed to be caused by the phase transition of propanal, which occurs during the desorption of propanal, as verified by the sharpening of the IR peaks in the RAIR spectra that are recorded at different temperatures (not shown here). Because propanal is mixed with other species in 


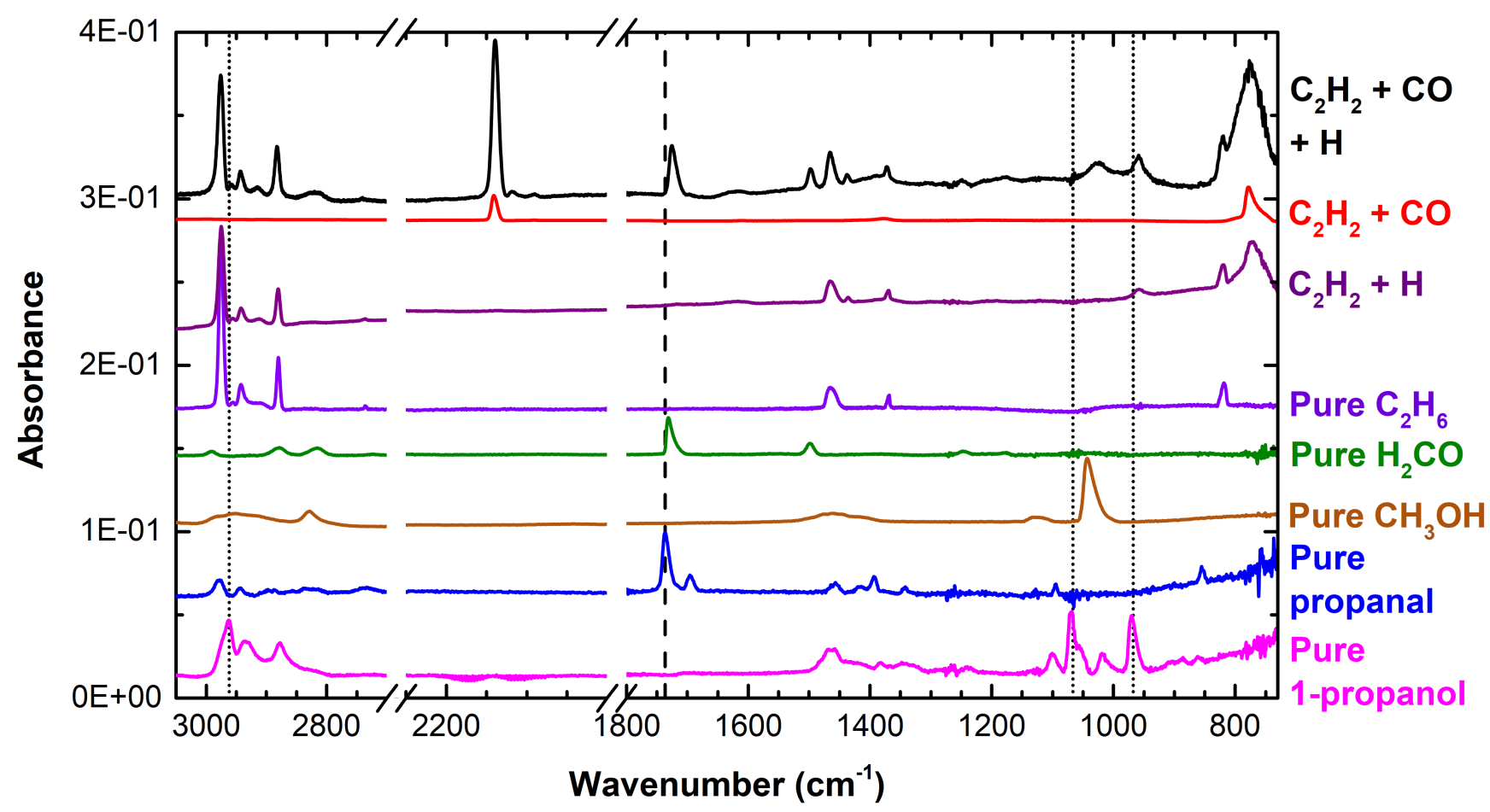

Fig. 1. RAIR spectra obtained after the deposition of $\mathrm{C}_{2} \mathrm{H}_{2}+\mathrm{CO}+\mathrm{H}$ (exp. 1.0), $\mathrm{C}_{2} \mathrm{H}_{2}+\mathrm{H}$ (exp. 1.2), 1-propanol (exp. 2.0), $\mathrm{CH}_{3} \mathrm{OH}\left(5 \times 10^{15} \mathrm{~cm}^{-2}\right)$, propanal (exp. 2.3), $\mathrm{H}_{2} \mathrm{CO}\left(5 \times 10^{15} \mathrm{~cm}^{-2}\right), \mathrm{C}_{2} \mathrm{H}_{6}\left(5 \times 10^{15} \mathrm{~cm}^{-2}\right)$, and $\mathrm{C}_{2} \mathrm{H}_{2}+\mathrm{CO}$ (exp. 1.1) on a $10 \mathrm{~K}$ surface. The spectrum of $\mathrm{C}_{2} \mathrm{H}_{6}$ is adapted from the work by Öberg et al. (2009). The dashed and dotted lines highlight the frequencies that correlate to the strongest features of propanal and 1-propanol, respectively. Spectra are scaled to highlight the IR features of interest, and are offset for clarity.

Table 2. Assigned IR absorption features in the co-deposition of $\mathrm{C}_{2} \mathrm{H}_{2}+\mathrm{CO}+\mathrm{H}$ (exp. 1.0).

\begin{tabular}{ccccc}
\hline $\begin{array}{c}\text { Peak position } \\
\left(\mathrm{cm}^{-1}\right)\end{array}$ & $\begin{array}{c}\text { Peak position } \\
(\mu \mathrm{m})\end{array}$ & Molecule & Mode & References \\
\hline 776 & 12.887 & $\mathrm{C}_{2} \mathrm{H}_{2}$ & $v_{5}$ & This work \\
820 & 12.195 & $\mathrm{C}_{2} \mathrm{H}_{6}$ and $\mathrm{C}_{2} \mathrm{H}_{4}$ & $v_{12}$ and $v_{10}$ & a,b,c,d,e,f,g,h,i \\
959 & 10.428 & $\mathrm{C}_{2} \mathrm{H}_{4}$ & $v_{7}$ & $\mathrm{a}, \mathrm{b}, \mathrm{c}, \mathrm{e}, \mathrm{f}, \mathrm{g}, \mathrm{h}, \mathrm{i}, \mathrm{j}$ \\
1025 & 9.756 & $\mathrm{CH}_{3} \mathrm{OH}_{8}$ & $v_{8}$ & $\mathrm{k}, \mathrm{l}$ \\
1371 & 7.294 & $\mathrm{C}_{2} \mathrm{H}_{6}$ & $v_{6}$ & $\mathrm{a}, \mathrm{b}, \mathrm{d}, \mathrm{e}, \mathrm{f}, \mathrm{g}, \mathrm{h}, \mathrm{i}$ \\
1438 & 6.954 & $\mathrm{C}_{2} \mathrm{H}_{4}$ & $v_{12}$ & $\mathrm{a}, \mathrm{b}, \mathrm{c}, \mathrm{d}, \mathrm{f}, \mathrm{g}, \mathrm{h}, \mathrm{i}$ \\
1466 & 6.821 & $\mathrm{C}_{2} \mathrm{H}_{6}$ & $v_{11}$ or $v_{8}$ & $\mathrm{a}, \mathrm{b}, \mathrm{c}, \mathrm{d}, \mathrm{e}, \mathrm{f}, \mathrm{g}, \mathrm{h}, \mathrm{i}$ \\
1498 & 6.676 & $\mathrm{H}_{2} \mathrm{CO}_{3}$ & $v_{3}$ & $\mathrm{k}, \mathrm{l}$ \\
1726 & 5.794 & $\mathrm{H}_{2} \mathrm{CO}$ & $v_{2}$ & $\mathrm{k}, \mathrm{l}$ \\
2138 & 4.677 & $\mathrm{CO}_{1}$ & $v_{1}$ & $\mathrm{k}, \mathrm{l}$ \\
2882 & 3.470 & $\mathrm{C}_{2} \mathrm{H}_{6}$ & $v_{5}$ & $\mathrm{a}, \mathrm{b}, \mathrm{c}, \mathrm{e}, \mathrm{f}, \mathrm{g}, \mathrm{h}, \mathrm{i}$ \\
2915 & 3.431 & $\mathrm{C}_{2} \mathrm{H}_{6}$ & $v_{8}+v_{11}$ & $\mathrm{e}, \mathrm{c}$ \\
2943 & 3.398 & $\mathrm{C}_{2} \mathrm{H}_{6}$ & $v_{8}+v_{11}$ & $\mathrm{a}, \mathrm{b}, \mathrm{c}, \mathrm{d}, \mathrm{e}, \mathrm{f}, \mathrm{g}, \mathrm{h}$ \\
2958 & 3.381 & $\mathrm{C}_{2} \mathrm{H}_{6}$ & $v_{1}$ & $\mathrm{e}, \mathrm{g}$ \\
2976 & 3.360 & $\mathrm{C}_{2} \mathrm{H}_{6}$ and $\mathrm{C}_{2} \mathrm{H}_{4}$ & $v_{10}$ and $v_{11}$ & a,c,d,e,f,g,h,i \\
\hline
\end{tabular}

References. ${ }^{(a)}$ Kim et al. (2010). ${ }^{(b)}$ Zhou et al. (2014). ${ }^{(c)}$ Abplanalp et al. (2018b). ${ }^{(d)}$ Gerakines et al. (1996). ${ }^{(e)}$ Abplanalp \& Kaiser (2016). ${ }^{(f)}$ Moore \& Hudson (1998). ${ }^{\left({ }^{g}\right)}$ Bennett et al. (2006). ${ }^{\left({ }^{h}\right)}$ Moore \& Hudson (2003). ${ }^{(i)}$ Hudson et al. (2014). ${ }^{(j)}$ Kobayashi et al. (2017). ${ }^{(k)}$ Watanabe \& Kouchi (2002). ${ }^{(l)}$ Chuang et al. (2016).

the $\mathrm{C}_{2} \mathrm{H}_{2}+\mathrm{CO}+\mathrm{H}$ experiment, it is much harder for these molecules to rearrange into the crystalline form, hence the lack of the phase transition shoulder in the top left figure. The fragmentation pattern involving the $\mathrm{C}_{3} \mathrm{H}_{6} \mathrm{O}^{+}(m / z=58)$ and $\mathrm{C}_{3} \mathrm{H}_{5} \mathrm{O}^{+}$ $(\mathrm{m} / \mathrm{z}=57)$ ions that derive from propanal is shown (Fig. 2, (right)) to complement the TPD findings. A fragmentation pattern of $33: 100,32: 100,36: 100$, and 30:100 is measured for the two ions from experiments $2.3,1.0,1.3$, and 1.4 , respectively. It is clear that the fragmentation pattern between the isotopically enhanced reactions is consistent and additionally their average value matches that of the pattern seen in the pure propanal experiment. The information from the discussed TPD experiments supports the hypothesis that propanal is formed in the $\mathrm{C}_{2} \mathrm{H}_{2}+$ $\mathrm{CO}+\mathrm{H}$ experiment.

Due to the limited abundance of the formed propanal starting from $\mathrm{C}_{2} \mathrm{H}_{2}+\mathrm{CO}+\mathrm{H}$ and the desorption of side products 

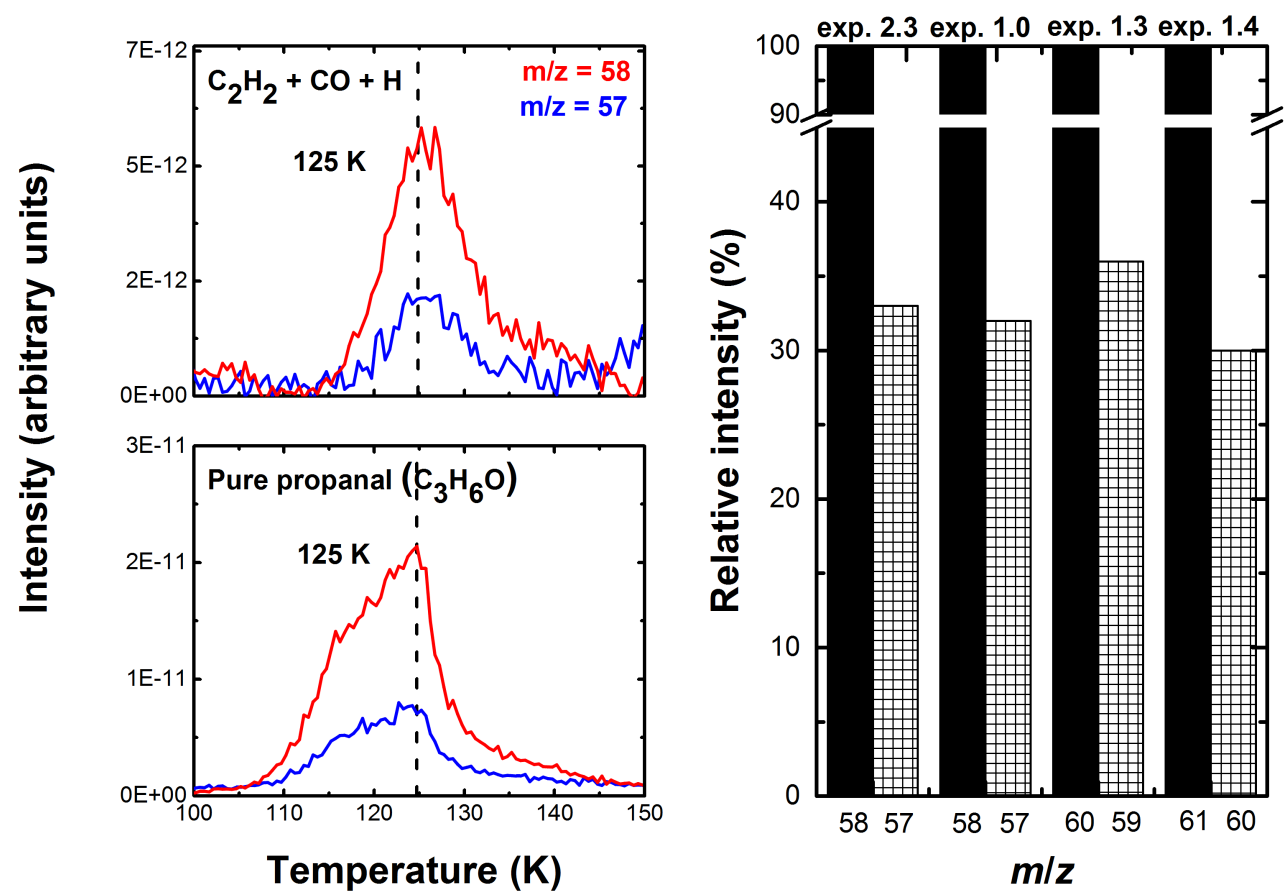

Fig. 2. Left panel: TPD spectra of $\mathrm{C}_{2} \mathrm{H}_{2}$ $+\mathrm{CO}+\mathrm{H}($ top; exp. 1.0) and propanal (bottom; exp. 2.3) taken after deposition at $10 \mathrm{~K}$. Right panel: QMS fragmentation pattern of two $\mathrm{m} / \mathrm{z}$ values that are normalized to the QMS signal of the $\mathrm{C}_{3} \mathrm{H}_{6} \mathrm{O}^{+}$ion (or the corresponding isotopologue) found in the propanal (exp. 2.3), $\mathrm{C}_{2} \mathrm{H}_{2}+\mathrm{CO}+\mathrm{H}($ exp. 1.0), $\mathrm{C}_{2} \mathrm{H}_{2}+\mathrm{C}^{18} \mathrm{O}+\mathrm{H}(\exp .1 .3)$, and $\mathrm{C}_{2} \mathrm{H}_{2}+$ ${ }^{13} \mathrm{C}^{18} \mathrm{O}+\mathrm{H}$ (exp. 1.4) experiments.

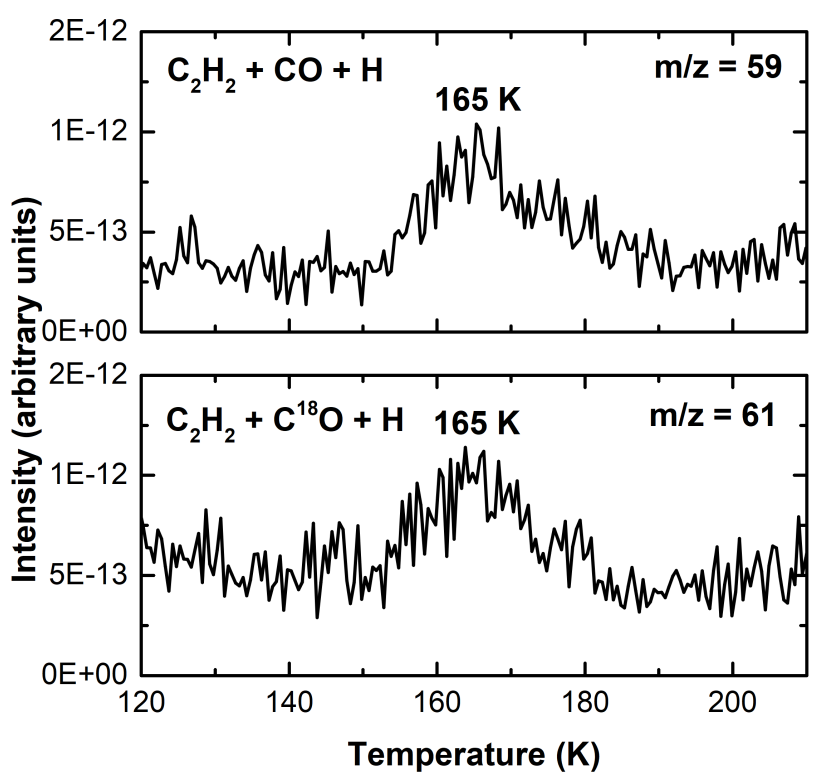

Fig. 3. TPD spectra that include $m / z$ values that may represent the desorption of 1-propanol. TPD of the reactions, $\mathrm{C}_{2} \mathrm{H}_{2}+\mathrm{CO}+\mathrm{H}$ (top; exp. 1.0) and $\mathrm{C}_{2} \mathrm{H}_{2}+\mathrm{C}^{18} \mathrm{O}+\mathrm{H}$ (bottom; exp. 1.3), taken after deposition at $10 \mathrm{~K}$.

that appear around the desorption of pure 1-propanol (e.g., glycolaldehyde), the detection of 1-propanol starting from a propanal-poor sample is just around the limit of our detection capabilities. Figure 3 shows TPD spectra of $\mathrm{m} / \mathrm{z}$ values that are tentatively identified as the $\mathrm{C}_{3} \mathrm{H}_{7} \mathrm{O}^{+}$and $\mathrm{C}_{3} \mathrm{H}_{7}{ }^{18} \mathrm{O}^{+}$ions of 1-propanol. These $\mathrm{m} / \mathrm{z}$ values (59 and 61) are selected as they should not appear for glycolaldehyde desorption, which occurs already around $160 \mathrm{~K}$. The peak desorptions at $165 \mathrm{~K}$ are shifted $+10 \mathrm{~K}$ from the peak desorption temperature of pure 1-propanol $(155 \mathrm{~K})$, which can be explained by the desorption of 1-propanol from the bare substrate surface and/or sub-monolayer regime. In this case, molecules occupy spots with higher binding energies. Although the signal intensities between the two desorption peaks are similar and both $\mathrm{m} / \mathrm{z}$ values peak at the same temperature, more information (i.e., more $\mathrm{m} / \mathrm{z}$ channels) is needed to conclusively prove that 1-propanol formation can also be directly detected in the $\mathrm{C}_{2} \mathrm{H}_{2}+\mathrm{CO}+\mathrm{H}$ experiment. For this reason, we present results for the hydrogenation of propanal, which is shown in the following section. A similar two-step approach was used in a previous study to confirm the formation of glycerol from $\mathrm{CO}+\mathrm{H}$ (Fedoseev et al. 2017).

\subsection{Formation of 1-propanol by solid-state hydrogenation of propanal}

To confirm the formation of 1-propanol by solid-state hydrogenation of propanal ice, TPD spectra were collected and are presented in Fig. 4. The TPD spectra of propanal $+\mathrm{H}$, propanal, and 1-propanol for $m / z=29,31,59$, and 60 are displayed top-down in the left panel, as these $m / z$ values are representative of the ions produced when propanal and 1propanol are fragmented by the QMS ionization source. For a pure propanal ice, the desorption peaks of $m / z=29,31$, and 59 appear at $125 \mathrm{~K}$, and are also found in the propanal + $\mathrm{H}$ experiment, as expected. In the propanal $+\mathrm{H}$ experiment, desorption peaks of $m / z=29,31,59$, and 60 appear also at $155 \mathrm{~K}$, which are observed in the 1-propanol experiment. To confirm that the signals at $155 \mathrm{~K}$ in the propanal $+\mathrm{H}$ experiment are due to the desorption of 1-propanol ice, the fragmentation patterns of the $m / z$ values found in the propanal $+\mathrm{H}$ and pure 1-propanol experiments were compared (right panel). The relative intensities in the propanal $+\mathrm{H}$ experiment are 19:100, 3:100, and 2:100 for $m / z=29: 31, m / z=59: 31$, and $m / z=60: 31$, respectively. These relative intensity values are almost identical to those found in the 1-propanol reference experiment, which are 15:100, 4:100, and 2:100 for these three $\mathrm{m} / \mathrm{z}$ values. This confirms that 1-propanol is derived from the hydrogenation of propanal at $10 \mathrm{~K}$.

To further complement the results from Fig. 4, the formation of 1-propanol from the hydrogenation of propanal can be tentatively identified from the RAIRS annealing series (RAIR spectra recorded at different temperatures) presented in Fig. 5. The feature at $860 \mathrm{~cm}^{-1}$ is assigned to the $\mathrm{CH}_{3}$ rocking mode of 

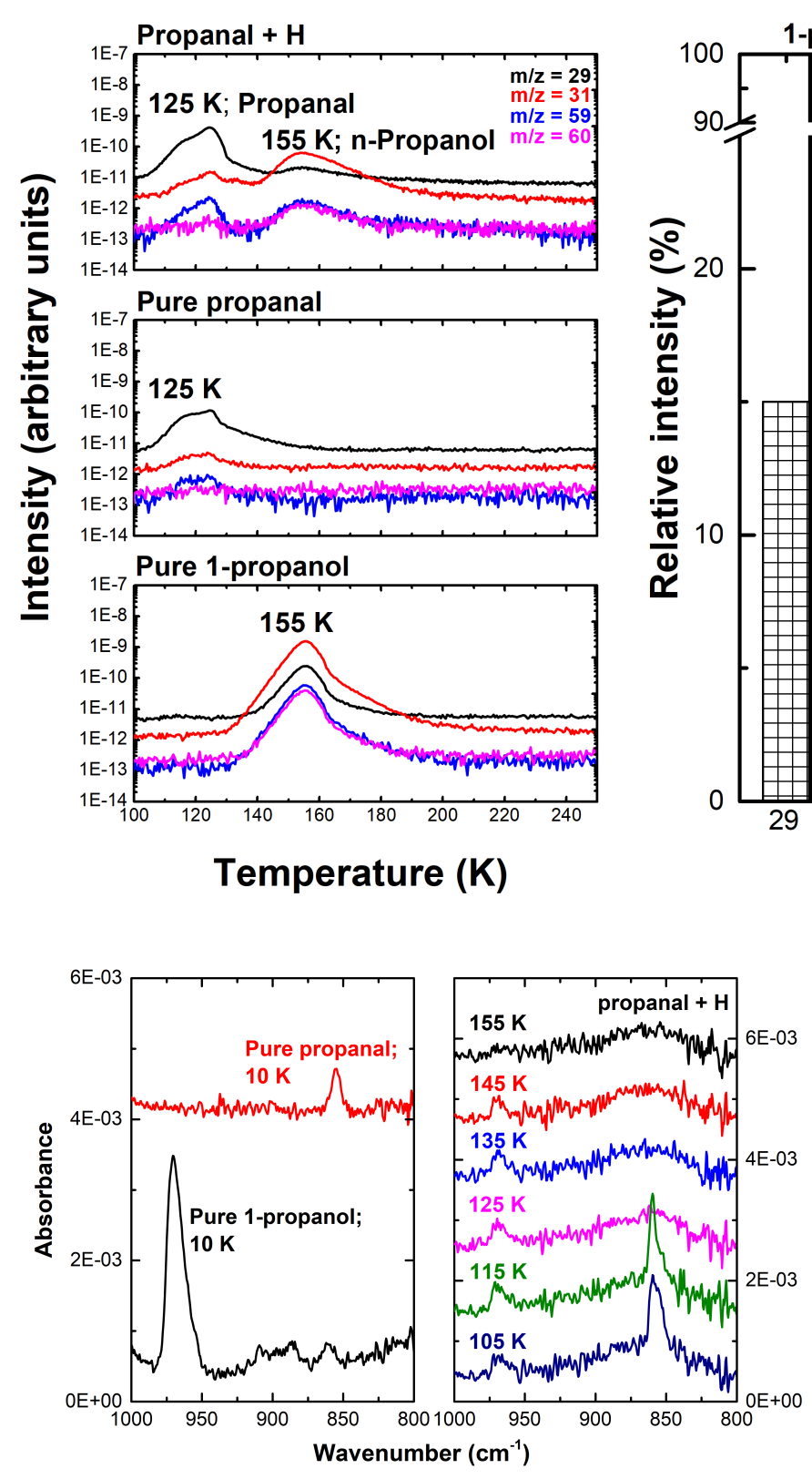

Fig. 5. Left panel: infrared features of pure propanal (exp. 2.3) and 1propanol (exp. 2.0). Right panel: RAIRS annealing series of propanal + $\mathrm{H}$ (exp. 2.1), taken after deposition at $10 \mathrm{~K}$. We note that the features at $860 \mathrm{~cm}^{-1}$ and $969 \mathrm{~cm}^{-1}$ are signatures of propanal and newly formed 1-propanol (tentative), as the signatures disappear by $125 \mathrm{~K}$ (propanal peak desorption temperature) and $155 \mathrm{~K}$ (1-propanol peak desorption temperature), respectively. RAIR spectra are offset for clarity.

propanal (Köroğlu et al. 2015) and the band at $969 \mathrm{~cm}^{-1}$ overlaps nicely with the C-O stretching frequency of 1-propanol (Max et al. 2002). As seen in the figure, the propanal band disappears at $125 \mathrm{~K}$, which is in-line with the peak desorption temperature of $125 \mathrm{~K}$ for propanal, as demonstrated in Fig. 4. The $969 \mathrm{~cm}^{-1}$ feature disappears at $155 \mathrm{~K}$, which is also the peak desorption temperature of 1-propanol. The results from Fig. 5 provide additional evidence of 1-propanol formation from propanal $+\mathrm{H}$, even though the figure only shows one potential band of 1-propanol. Other RAIR bands of 1-propanol cannot be positively identified or probed largely due to the low signal-to-noise ratio $(\mathrm{S} / \mathrm{N})$ of
Pure 1-propanol Propanal $+\mathrm{H}$

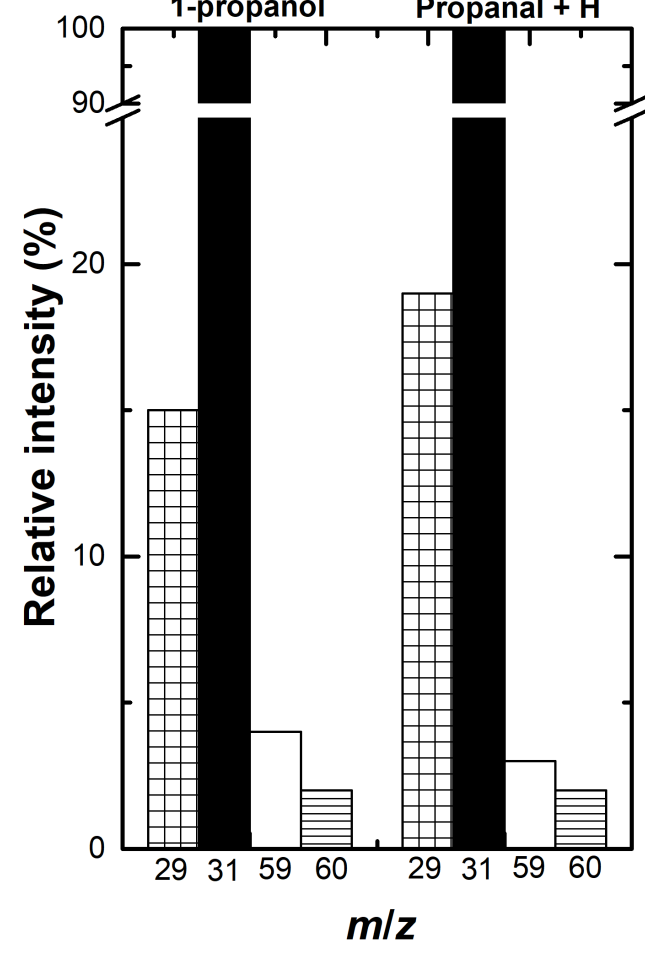

Fig. 4. Left panel: TPD of propanal $+\mathrm{H}$ (top; exp. 2.2), propanal (middle; exp. 2.3), and 1-propanol (bottom; exp. 2.0) taken after deposition at $10 \mathrm{~K}$. Right panel: QMS fragmentation pattern of four $\mathrm{m} / \mathrm{z}$ values that are normalized to the QMS signal of $m / z=31$ found in the 1-propanol (exp. 2.0) and propanal $+\mathrm{H}$ (exp. 2.2) experiments for a temperature of $125 \mathrm{~K}$.

the new bands in experiment 2.1. The data shown in Fig. 5 support the results from the TPD experiments that are presented in Fig. 4.

\section{Discussion}

Figure 6 shows a list of possible pathways that hold the potential to form propanal and 1-propanol by the co-deposition of $\mathrm{C}_{2} \mathrm{H}_{2}+$ $\mathrm{CO}+\mathrm{H}$ under our experimental conditions. These aim to mimic interstellar conditions as closely as possible, but one must bear in mind that mixed $\mathrm{CO}: \mathrm{C}_{2} \mathrm{H}_{2}$ ices are likely not representative for interstellar ices. Here, we mainly aim at reproducing conditions that allow to study reaction pathways that will be at play in interstellar ices. The two left-most reaction chains in Fig. 6 show how the reacting radicals and stable molecules from the hydrogenation of $\mathrm{CO}\left(\mathrm{HCO}, \mathrm{H}_{2} \mathrm{CO}, \mathrm{CH}_{3} \mathrm{O}\right.$, and $\left.\mathrm{CH}_{2} \mathrm{OH}\right)$ and $\mathrm{C}_{2} \mathrm{H}_{2}$ $\left(\mathrm{H}_{2} \mathrm{CCH}, \mathrm{H}_{2} \mathrm{CCH}_{2}\right.$, and $\left.\mathrm{H}_{3} \mathrm{CCH}_{2}\right)$ are formed. We note that $\mathrm{CO}$ and $\mathrm{C}_{2} \mathrm{H}_{2}$ do not react with each other under our experimental conditions. From this set of radicals and molecules, the combination of which most likely leads to the formation of propanal and 1-propanol is discussed here first by process of elimination. The barrier value for $\mathrm{H}$-abstraction from $\mathrm{C}_{2} \mathrm{H}_{2}$ is $>56000 \mathrm{~K}$ (Zhou et al. 2008), which is very high for thermalized $\mathrm{H}$-atoms to bypass at cryogenic temperatures used in our experiments. This $\mathrm{H}$-abstraction is required for species - such as propynal to be formed. Therefore, the pathways involving the formation of propynal are excluded from our reaction network. A direct consequence of this is that the $\mathrm{C} \equiv \mathrm{C}$ bond must be converted to a single $\mathrm{C}-\mathrm{C}$ bond by $\mathrm{H}$-atom addition, as demonstrated in the works of Hiraoka et al. (2000) and Kobayashi et al. (2017).

Radical-molecule reactions, such as those between the HCO radical and $\mathrm{C}_{2} \mathrm{H}_{2}$ or $\mathrm{C}_{2} \mathrm{H}_{4}$ molecules, can also be excluded due to their high activation barriers. These activation energies are calculated following the method described by Kobayashi et al. (2017) and Zaverkin et al. (2018). Briefly, the electronic 
D. Qasim et al.: Formation of interstellar propanal and 1-propanol ice
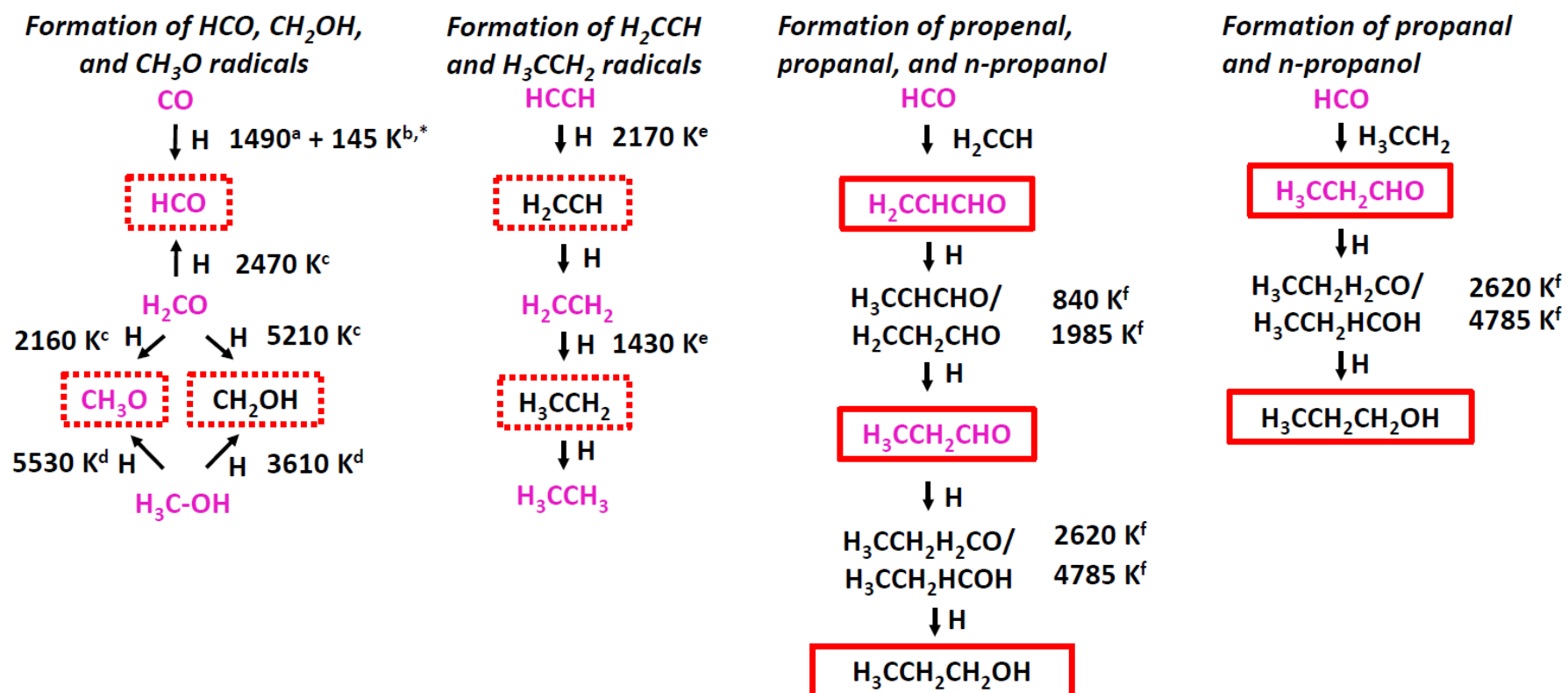

$\mathrm{H}_{3} \mathrm{CCH}_{2} \mathrm{CH}_{2} \mathrm{OH}$

Fig. 6. Proposed mechanisms for experiment 1.0. We note that all radical-radical reactions shown here are barrierless. Relevant species within each mechanism are boxed; solid-line boxes indicate stable species and dotted-line boxes indicate radicals. Species labelled with purple font are those that have been detected in space. Activation energies are by (a) Andersson et al. (2011), (b) Álvarez-Barcia et al. (2018), (c) Song \& Kästner (2017), (d) Goumans \& Kästner (2011), (e) Kobayashi et al. (2017), and (f) Zaverkin et al. (2018). An asterisk indicates the zero-point energy (ZPE) contribution.

structure is described by density functional theory (DFT) with the MPWB1K functional (Zhao \& Truhlar 2004) and the def2-TZVP basis set (Weigend et al. 1998). This combination has been shown to yield good results via benchmark studies. The activation energies are calculated including ZPE and with respect to the pre-reactive complex. Transition state geometries are listed in Table B.1. These values are determined for the gas-phase, which will yield representative values as we expect the influence of the predominantly CO-rich environment to play a minor role in altering the reaction potential energy landscape. We find the activation energy for the reaction $\mathrm{HCO}+\mathrm{C}_{2} \mathrm{H}_{2} \rightarrow \mathrm{HCCHCHO}$ to be $4290 \mathrm{~K}$ and that for the reaction $\mathrm{HCO}+\mathrm{C}_{2} \mathrm{H}_{4} \rightarrow \mathrm{H}_{2} \mathrm{CCH}_{2} \mathrm{CHO}$ to be $3375 \mathrm{~K}$. Such high barriers hint at a low overall efficiency, especially because, as indicated by Álvarez-Barcia et al. (2018), reactions where two heavy atoms are involved, for example formation of a carboncarbon bond, are expected not to tunnel efficiently. Such barriers could be overcome if the HCO radical would have considerable leftover excess energy after formation.

With the exclusion of $\mathrm{H}$-abstraction reactions involving stable hydrocarbon molecules and also radical-neutral reactions, the following reactions are left to consider: $\mathrm{HCO}+$ $\mathrm{H}_{2} \mathrm{CCH} / \mathrm{H}_{3} \mathrm{CCH}_{2}, \mathrm{CH}_{3} \mathrm{O}+\mathrm{H}_{2} \mathrm{CCH} / \mathrm{H}_{3} \mathrm{CCH}_{2}$, and $\mathrm{CH}_{2} \mathrm{OH}+$ $\mathrm{H}_{2} \mathrm{CCH} / \mathrm{H}_{3} \mathrm{CCH}_{2}$. Of these, only $\mathrm{HCO}+\mathrm{H}_{2} \mathrm{CCH} / \mathrm{H}_{3} \mathrm{CCH}_{2}$ leads to the formation of both - propanal and 1-propanol. As shown in Fig. 6, propenal can be formed by $\mathrm{HCO}+\mathrm{H}_{2} \mathrm{CCH}$. Propenal was not detected in our experiments, and this is likely due to the low activation barrier of $842 \mathrm{~K}$ for propenal $+\mathrm{H}$ (Zaverkin et al. 2018), effectively converting propenal to further hydrogenation products. $\mathrm{CH}_{3} \mathrm{O}$ and $\mathrm{CH}_{2} \mathrm{OH}$ radicals may react with hydrocarbon radicals to form methoxyethene, methoxyethane, allyl alcohol, and 1-propanol. Yet, these radicals are further down the $\mathrm{CO}+\mathrm{H}$ chain, and since $\mathrm{H}_{2} \mathrm{CO}+\mathrm{H}$ has a barrier of $>2000$ K (Woon 2002; Song \& Kästner 2017), reactions with $\mathrm{CH}_{3} \mathrm{O}$ and $\mathrm{CH}_{2} \mathrm{OH}$ radicals are less probable than with $\mathrm{HCO}$ under our experimental conditions. However, it should be noted that interstellar $\mathrm{CH}_{3} \mathrm{OH}$ (ice and gas) is an abundant molecule that is primarily formed by the $\mathrm{CO}+\mathrm{H}$ surface reaction, thus $\mathrm{CH}_{3} \mathrm{O}$ and $\mathrm{CH}_{2} \mathrm{OH}$ radicals must also be abundant in the ISM. Therefore other primary alcohols, aldehydes, and even ethers maybe formed with abundances that can be used to search for astrochemical links.

Comparison of the hydrogenation activation barriers of $\mathrm{H}_{2} \mathrm{CO}$ and propanal shows that the values have a difference of $<500 \mathrm{~K}$ (with $\mathrm{H}_{2} \mathrm{CO}+\mathrm{H}$ having the smaller barrier), although the low-temperature rate constant is greater for the case of $\mathrm{H}_{2} \mathrm{CO}$. Since hydrogenation of $\mathrm{H}_{2} \mathrm{CO}$ is the dominating pathway to $\mathrm{CH}_{3} \mathrm{OH}$ formation in interstellar space, this means that also the hydrogenation of propanal resulting in the formation of interstellar 1-propanol maybe a notable pathway.

The work by Jonusas et al. (2017), in which propanal hydrogenation was not found to result in 1-propanol formation, seems to be in contradiction with our findings. A direct comparison is hard, since the hydrogen and propanal fluxes and fluences, and particularly the deposition methods, are different between the two studies. Jonusas et al. (2017) deposited propanal first, then bombarded the ice with hydrogen atoms. This is known as the pre-deposition method, which results in less product formation in comparison to the co-deposition method usually because of the limited penetration depth of hydrogen atoms in the ice, as discussed by Fuchs et al. (2009) in the case of $\mathrm{CO}+\mathrm{H}$. The theoretical work by Zaverkin et al. (2018) suggested that the non-detection of 1-propanol by Jonusas et al. (2017) could be due to the continuous $\mathrm{H}$-abstraction and subsequent $\mathrm{H}$-addition from and onto the carbonyl- $\mathrm{C}$, respectively, since $\mathrm{H}$-abstraction from the carbonyl-C of propanal was found to be five orders of magnitude faster than $\mathrm{H}$-addition to $\mathrm{O}$ at $60 \mathrm{~K}$ (we note that the experiments presented here occur at $10 \mathrm{~K}$ ). Another scenario could exist: after $\mathrm{H}$-abstraction from the carbonyl-C, the resulting radical could be more prone to hydrogenation on the $\mathrm{O}$, 
which would favour 1-propanol formation. However, there are no rate constants or branching ratios available for that process.

Finally, we address the dominant reaction mechanism. Reactions that take place on surfaces such as that studied here usually have three mechanisms: Langmuir-Hinshelwood (L-H), Eley-Rideal (E-R), and hot-atom (H-A; He et al. 2017). In the presented experiments, the ice temperature is at $10 \mathrm{~K}$ during the deposition. This allows the residence time of $\mathrm{H}$-atoms to be long enough for the atoms to rapidly scan the surface and have multiple chances of reaction with other ice reactants. Further, the rate of reaction via the $\mathrm{L}-\mathrm{H}$ mechanism dominates over $\mathrm{E}-\mathrm{R}$ and $\mathrm{H}-\mathrm{A}$ mechanisms especially when the reaction possesses a significant activation barrier. As demonstrated by Watanabe \& Kouchi (2002), Watanabe et al. (2003), Cuppen \& Herbst (2007), Fuchs et al. (2009), Chuang et al. (2016), and Qasim et al. (2018), the abundance of products that are formed from hydrogenation decreases substantially as the deposition temperature increases to temperatures that are below the initial desorption temperature of the reactant molecule(s). This is due to the rapid drop of the $\mathrm{H}$-atom residence time on the surface. If the $\mathrm{E}-\mathrm{R}$ or $\mathrm{H}-\mathrm{A}$ mechanism were responsible for the formation of products, then no drastic drop in the amount of the formed products would be observed. This evidence in favour of the $\mathrm{L}-\mathrm{H}$ mechanism also allows us to claim that the $\mathrm{H}$-atoms involved in the reactions are in thermal equilibrium with the $10 \mathrm{~K}$ surface.

\section{Astrophysical implications}

The experimental conditions and chemical species studied aim to mimic reaction pathways that can take place on icy dust grains in a cold and dense prestellar core or the outer regions of protostellar envelopes (i.e., $10 \mathrm{~K}$ ices formed primarily by radical-induced reactions). Specifically, we have investigated how species formed along the well-studied $\mathrm{CO}$ hydrogenation chain can interact with radicals formed upon hydrogenation of other species expected to be present in an interstellar ice environment. Newly formed ice constituents can then be observed in the gas-phase after warm-up in the hot core region following thermal desorption. Following the outcome of our experiments, the detection of propanal in hot cores may be explained following the reaction scheme discussed in Fig. 6 and the formation of 1-propanol is a logical consequence, providing solid motivation for future surveys for this species. $\mathrm{C}_{2} \mathrm{H}_{2}$ was used in the experiments as a source for hydrocarbon radicals, which are species that can also be formed in different ways in the ISM. Strong lines of gaseous $\mathrm{C}_{2} \mathrm{H}_{2}$ have been detected in warm gas in protostellar envelopes (Lacy et al. 1989; Lahuis \& Van Dishoeck 2000; Rangwala et al. 2018) and in protoplanetary disks (Gibb et al. 2007; Carr \& Najita 2008; Salyk 2011), with typical abundances of $10^{-7}-10^{-6}$ with respect to $\mathrm{H}_{2}$, or $10^{-3}-10^{-2}$ with respect to gaseous $\mathrm{H}_{2} \mathrm{O}$ or $\mathrm{CO}$. However, there has not yet been a detection of interstellar solid $\mathrm{C}_{2} \mathrm{H}_{2}$. The limits on $\mathrm{C}_{2} \mathrm{H}_{2}$ ice are $<1.4 \%$ with respect to $\mathrm{H}_{2} \mathrm{O}$ ice (Boudin et al. 1998), which is similar to or lower than the abundance of $\mathrm{CH}_{4}$ ice (typical abundance of 5\%; Gibb et al. 2004; Öberg et al. 2008, 2011; Boogert et al. 2015). Other models of gas-grain chemistry predict lower $\mathrm{C}_{2} \mathrm{H}_{2}$ abundances; a factor of 50-100 lower than that of $\mathrm{CH}_{4}$ (Garrod 2013). In cometary ices, $\mathrm{C}_{2} \mathrm{H}_{2}$ is detected, at a level of $0.1-0.5 \%$ with respect to $\mathrm{H}_{2} \mathrm{O}$ ice (Mumma \& Charnley 2011). A logical explanation for such low abundances is that the bulk of the solid $\mathrm{C}_{2} \mathrm{H}_{2}$ is transformed to other species, through reactions such as those studied here.

As stated in Sect. 1, 1-propanol has not yet been identified in the ISM, but several surveys have attempted its detection. Here we put the laboratory and theoretical findings presented in the previous sections into an astrochemical context, using deep interferometric observations by ALMA with the aim to constrain the abundance of 1-propanol around the hot core of the low-mass protostar IRAS 16293-2422B. We use the $12 \mathrm{~m}$ array ALMA data from the work by Taquet et al. (2018) under Cycle 4 (program 2016.1.01150.S) in Band 6 at 233-236 GHz. These observations have a circular Gaussian beam fixed to $0.5^{\prime \prime}$ and with a $1 \sigma \mathrm{rms}$ sensitivity of $1.2-1.4 \mathrm{mJy} \mathrm{beam}^{-1}$ per $0.156 \mathrm{~km} \mathrm{~s}^{-1}$ channel. This provides one of the deepest ALMA datasets towards a low-mass protostar obtained so far. Spectra of the four spectral windows obtained towards a position located at 1 beam size offset in the southwest direction with respect to the source B dust continuum position are analysed, which gives the best compromise between intensity and opacity of the continuum and the molecular emission. The observed and predicted spectra of the four spectral windows towards the full-beam offset position are shown in the appendix of Taquet et al. (2018). As explained there, more than 250 spectroscopic entries mostly using the CDMS and JPL catalogues have been taken into account to identify all detected transitions. However, as discussed by Taquet et al. (2018), $\sim 70 \%$ of the $\sim 670$ transitions remain unidentified at a $5 \sigma$ level. The full spectrum of 1-propanol over the entire frequency range is simulated (Fig. C.1) and compared with observations. The spectroscopic data of the 1-propanol molecule are provided by Kisiel et al. (2010). About 60 "bright" transitions (i.e. $E_{\mathrm{up}}<500 \mathrm{~K}, A_{\mathrm{i}, \mathrm{j}}>10^{-5} \mathrm{~s}^{-1}$ ) from 1-propanol are located in the frequency range covered by the four spectral windows. The transition that gives the deepest constraint on the column density of 1-propanol is that at $236.138 \mathrm{GHz}$ $\left(E_{\mathrm{up}}=160 \mathrm{~K}, A_{\mathrm{i}, \mathrm{j}}=6.6 \times 10^{-5} \mathrm{~s}^{-1}\right)$ as seen in Fig. C.1.

We derive the upper limit of the 1-propanol column density assuming conditions at the local thermal equilibrium (LTE) and assuming optically thin emission and excitation temperatures of 300 and $125 \mathrm{~K}$, following previous ALMA observations of other COMs towards this source (Jørgensen et al. 2018). Both panels in Fig. 7 show the spectrum around the targeted transition obtained after a baseline correction through a fit over the line-free regions around $236.138 \mathrm{GHz}$. We note that only the spectrum at $T_{\mathrm{ex}}=300 \mathrm{~K}$ is shown, since the spectrum for $T_{\mathrm{ex}}=125 \mathrm{~K}$ at around $236.138 \mathrm{GHz}$ is the same. The 1-propanol transition is blended by two lines at 236.1376 and at $236.1390 \mathrm{GHz}$, which is clearly visible from the zoom-in shown in the right panel. The former transition (on the left) could be partially attributed to $\mathrm{CH}_{2} \mathrm{NH}$, recently detected toward IRAS 16293-2422B by Ligterink et al. (2018) using ALMA. The peak on the right is of unknown nature and may be due to a rotational transition starting from a vibrationally excited species. With an offset of $0.15 \mathrm{MHz}$ with respect to the synthetic transition (red), it is unlikely that this peak is actually due to 1-propanol. Only a modification of the source velocity from $2.7 \mathrm{~km} \mathrm{~s}^{-1}$ - the source velocity of IRAS $16293-\mathrm{B}$ usually derived - to $2.5 \mathrm{~km} \mathrm{~s}^{-1}$ would result in a match. In that case, the next strongest transitions should be searched for. We verified that other "bright" 1-propanol lines are not detected in our observed spectrum for the two different upper limits and associated excitation temperatures. For the moment, we conclude that the transition to the right is not due to 1-propanol.

In order to derive a conservative limit for the 1-propanol column density, we neglect the spectral contribution of the two peaks shown in Fig. 7 near the wavelength of the predicted 1-propanol transition and instead derive the column density using the synthetic transition. At 300 and $125 \mathrm{~K}$, 1-propanol column densities of $1.2 \times 10^{15} \mathrm{~cm}^{-2}$ and $7.6 \times 10^{14} \mathrm{~cm}^{-2}$ are derived, respectively, which are the highest column densities 

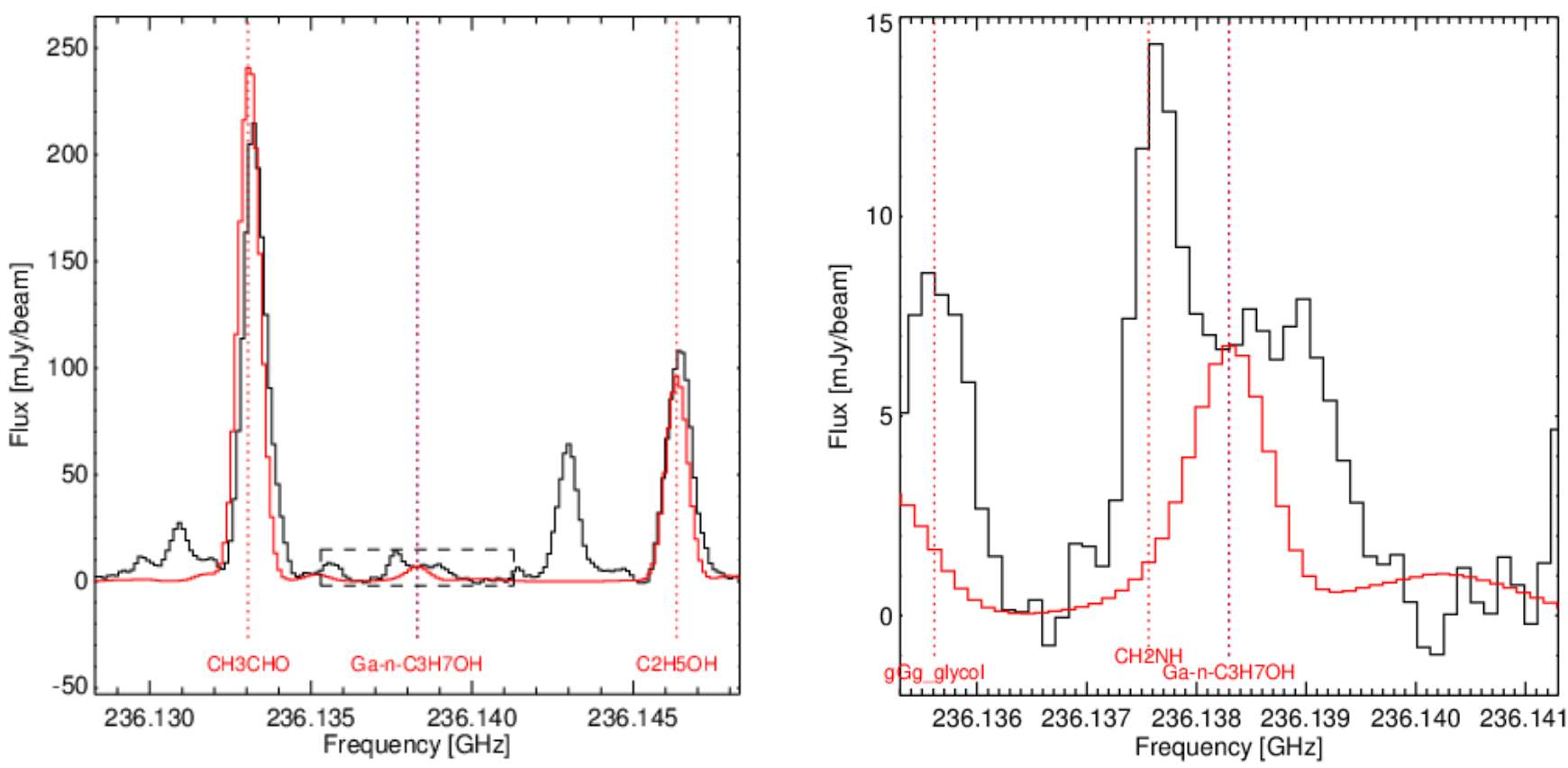

Fig. 7. Extended (left panel) and zoomed-in (right panel) spectra around the 1-propanol transition. Observed spectrum (black) around the targeted 1-propanol transition at $236.138 \mathrm{GHz}$ (purple dotted-line and black dashed-line box) towards the "full-beam" offset position located 0.5" away from the continuum peak of IRAS 16293-2422B. Synthetic spectrum of the LTE model is shown in red. The predicted 1-propanol transition shown here is for $N\left(1\right.$-propanol) $=1.2 \times 10^{15} \mathrm{~cm}^{-2}$ and $T_{\mathrm{ex}}=300 \mathrm{~K}$ (see text for more details). Red dotted-lines refer to the position of transitions of identified species detected above $5 \sigma$, with the associated species labelled below the spectrum.

that still result in a non-detection of 1-propanol. Comparing this value to the propanal column density of $2.2 \times 10^{15} \mathrm{~cm}^{-2}$ found by Lykke et al. (2017) for $125 \mathrm{~K}$ with similar observational properties, this results in a 1-propanol:propanal upper limit of $<0.55\left(T_{\mathrm{ex}}=300 \mathrm{~K}\right)$ and $<0.35\left(T_{\mathrm{ex}}=125 \mathrm{~K}\right)$. This is consistent with the experiments in this work and also with the theoretical calculations by Zaverkin et al. (2018), which show that the hydrogenation of propanal to 1-propanol involves a barrier. From the perspective that only the activation barrier is considered, there should be less 1-propanol in space in comparison to propanal if 1-propanol originates from propanal.

The $\mathrm{C}_{2} \mathrm{H}_{2}+\mathrm{CO}+\mathrm{H}$ experiment shows the importance of introducing different molecules to the $\mathrm{CO}+\mathrm{H}$ channel. The $\mathrm{CO}$ hydrogenation chain is generally taken as the way to explain the observed $\mathrm{CH}_{3} \mathrm{OH}$ abundances in space under dark cloud conditions. In recent work, an extension of this network towards larger sugars and sugar alcohols was proven. Here we demonstrate that this reaction chain also holds potential for the formation of other species, including radicals formed by other means. By adding $\mathrm{C}_{2} \mathrm{H}_{2}$, reaction pathways are realised in which 1-propanol can be formed. This is significant, as the molecule has astrobiological relevance and may already be formed during the dark cloud stage, for example when particularly "non-energetic" processes are at play. It is clear from the detections and proposed list of mechanisms in this work that the extension of the $\mathrm{CO}+\mathrm{H}$ channel is promising to explain the formation of potentially important interstellar species that have solid-state formation pathways that are not yet well understood.

From the studied reactions, it can be generalized that a whole set of various aldehydes and primary alcohols can be formed starting from $\mathrm{CO}$ and polyynes, where polyynes are composed of alkynes such as $\mathrm{C}_{2} \mathrm{H}_{2}$. Such molecules can directly participate in the formation of micelles, or serve as the analogues of fatty acids in the formation of glycerol esters (analogues of glycolipids). The latter is particularly intriguing since previous results indicate that glycerol is formed by hydrogenation of $\mathrm{CO}$ during the heavy CO freeze-out stage (Fedoseev et al. 2017).

\section{Conclusions}

This study focuses on the possible formation of the COMs, propanal and 1-propanol, that may take place when radicals formed in the hydrogenation of $\mathrm{C}_{2} \mathrm{H}_{2}$ and $\mathrm{CO}$ ice interact. For a temperature of $10 \mathrm{~K}$ and upon $\mathrm{H}$-atom addition during a $\mathrm{C}_{2} \mathrm{H}_{2}$ and $\mathrm{CO}$ co-deposition experiment, our findings can be summarised as follows.

- We find the formation of propanal and possibly 1-propanol ice.

- We show that the hydrogenation of propanal ice leads to 1-propanol formation. Further theoretical investigations on the scenario that favours 1-propanol formation are desired.

- We conclude that the most likely formation scheme of these two COMs is through the radical-radical reactions of $\mathrm{HCO}+$ $\mathrm{H}_{2} \mathrm{CCH}$ and $\mathrm{HCO}+\mathrm{H}_{3} \mathrm{CCH}_{2}$.

- We derive 1-propanol upper limits of $1.2 \times 10^{15} \mathrm{~cm}^{-2}$ $\left(T_{\text {ex }}=300 \mathrm{~K}\right)$ and $7.6 \times 10^{14} \mathrm{~cm}^{-2}\left(T_{\mathrm{ex}}=125 \mathrm{~K}\right)$ from ALMA observations towards the IRAS 16293-2422B low-mass protostar. These values are compared to the propanal column density of $2.2 \times 10^{15} \mathrm{~cm}^{-2}$ from Lykke et al. (2017). The 1-propanol:propanal abundance ratio of $<0.35-0.55$ is complemented by activation barriers of propanal $+2 \mathrm{H} \rightarrow 1$-propanol found in the presented experiments and in theoretical works.

Acknowledgements. This research would not have been possible without the financial support from the Dutch Astrochemistry Network II (DANII). Further support includes a VICI grant of NWO (the Netherlands Organization for Scientific Research) and A-ERC grant 291141 CHEMPLAN. Funding by NOVA (the Netherlands Research School for Astronomy) and the Royal Netherlands Academy of Arts and Sciences (KNAW) through a professor prize is acknowledged. D.Q. thanks Johannes Kästner for insightful discussions. G.F. 
and V.T. recognise the financial support from the European Union's Horizon 2020 research and innovation programme under the Marie Sklodowska-Curie grant agreement no. 664931. T.L. is supported by NWO via a VENI fellowship (722.017.00). S.I. recognises the Royal Society for financial support and the Holland Research School for Molecular Chemistry (HRSMC) for a travel grant This paper makes use of the following ALMA data: ADS/JAO.ALMA\#2016. 1.01150.S. ALMA is a partnership of ESO (representing its member states), NSF (USA) and NINS (Japan), together with NRC (Canada), MOST and ASIAA (Taiwan), and KASI (Republic of Korea), in cooperation with the Republic of Chile. The Joint ALMA Observatory is operated by ESO, AUI/NRAO and NAOJ.

\section{References}

Abplanalp, M. J., \& Kaiser, R. I. 2016, ApJ, 827, 132

Abplanalp, M. J., Gozem, S., Krylov, A. I., et al. 2016, Proc. Natl. Acad. Sci. USA, 113, 7727

Abplanalp, M. J., Góbi, S., Bergantini, A., Turner, A. M., \& Kaiser, R. I. 2018a, Chem. Phys. Chem., 19, 556

Abplanalp, M. J., Jones, B. M., \& Kaiser, R. I. 2018b, Phys. Chem. Chem. Phys., 20,5435

Altwegg, K., Balsiger, H., Berthelier, J.-J., et al. 2017, MNRAS, 469, S130

Álvarez-Barcia, S., Russ, P., Kästner, J., \& Lamberts, T. 2018, MNRAS, 479, 2007

Andersson, S., Goumans, T., \& Arnaldsson, A. 2011, Chem. Phys. Lett., 513, 31

Bennett, C. J., Jamieson, C. S., Osamura, Y., \& Kaiser, R. I. 2006, ApJ, 653 792

Bisschop, S., Fuchs, G., Van Dishoeck, E. F., \& Linnartz, H. 2007, A\&A, 474 1061

Boogert, A. A., Gerakines, P. A., \& Whittet, D. C. 2015, ARA\&A, 53, 541

Boudin, N., Schutte, W. A., \& Greenberg, J. M. 1998, A\&A, 331, 749

Butscher, T., Duvernay, F., Theule, P., et al. 2015, MNRAS, 453, 1587

Butscher, T., Duvernay, F., Rimola, A., Segado-Centellas, M., \& Chiavassa, T. 2017, Phys. Chem. Chem. Phys., 19, 2857

Carr, J. S., \& Najita, J. R. 2008, Science, 319, 1504

Chuang, K.-J., Fedoseev, G., Ioppolo, S., van Dishoeck, E. F., \& Linnartz, H 2016, MNRAS, 455, 1702

Chuang, K.-J., Fedoseev, G., Qasim, D., et al. 2018, ApJ, 853, 102

Cuppen, H., \& Herbst, E. 2007, ApJ, 668, 294

Cuppen, H., Ioppolo, S., Romanzin, C., \& Linnartz, H. 2010, Phys. Chem. Chem. Phys., 12, 12077

Deamer, D., Dworkin, J. P., Sandford, S. A., Bernstein, M. P., \& Allamandola, L. J. 2002, Astrobiology, 2, 371

de Marcellus, P., Meinert, C., Myrgorodska, I., et al. 2015, Proc. Natl. Acad. Sci. U.S.A., 112, 965

De Rosa, M., Gambacorta, A., \& Gliozzi, A. 1986, Microbiol. Rev., 50, 70

Fedoseev, G., Cuppen, H. M., Ioppolo, S., Lamberts, T., \& Linnartz, H. 2015 MNRAS, 448, 1288

Fedoseev, G., Chuang, K.-J., Ioppolo, S., et al. 2017, ApJ, 842, 52

Fuchs, G., Cuppen, H., Ioppolo, S., et al. 2009, A\&A, 505, 629

Garrod, R. T. 2013, ApJ, 765, 60

Gerakines, P., Schutte, W., \& Ehrenfreund, P. 1996, A\&A, 312, 289

Gibb, E., Whittet, D., Boogert, A., \& Tielens, A. 2004, ApJS, 151, 35

Gibb, E., Van Brunt, K., Brittain, S. D., \& Rettig, T. 2007, ApJ, 660, 1572

Goesmann, F., Rosenbauer, H., Bredehöft, J. H., et al. 2015, Science, 349, aab0689

Goumans, T., \& Kästner, J. 2011, J. Phys. Chem. A, 115, 10767

He, J., Emtiaz, S. M., \& Vidali, G. 2017, ApJ, 851, 104

Hiraoka, K., Takayama, T., Euchi, A., Handa, H., \& Sato, T. 2000, ApJ, 532, 1029
Hollis, J. M., Jewell, P. R., Lovas, F. J., Remijan, A., \& Møllendal, H. 2004, ApJ, 610, L21

Hudson, R. L., Gerakines, P. A., \& Moore, M. 2014, Icarus, 243, 148

Hudson, R., Loeffler, M., \& Yocum, K. 2017, ApJ, 835, 225

Ioppolo, S. 2014, in Laboratory Astrochemistry: From Molecules through Nanoparticles to Grains, eds. S. Schlemmer, T. Giesen, \& H. Mutschke (New York: John Wiley \& Sons), 289

Ioppolo, S., Fedoseev, G., Lamberts, T., Romanzin, C., \& Linnartz, H. 2013, Rev. Sci. Instrum., 84, 073112

Jonusas, M., Guillemin, J.-C., \& Krim, L. 2017, MNRAS, 468, 4592

Jørgensen, J., Müller, H., Calcutt, H., et al. 2018, A\&A, 620, A170

Kaiser, R. I., Maity, S., \& Jones, B. M. 2014, Phys. Chem. Chem. Phys., 16, 3399

Kim, Y., Bennett, C., Chen, L.-H., O’Brien, K., \& Kaiser, R. 2010, ApJ, 711, 744

Kisiel, Z., Dorosh, O., Maeda, A., et al. 2010, Phys. Chem. Chem. Phys., 12, 8329

Kobayashi, H., Hidaka, H., Lamberts, T., et al. 2017, ApJ, 837, 155

Kolasinski, K. W. 2012, Surface Science: Foundations of Catalysis and Nanoscience (Chichester: John Wiley \& Sons)

Köroğlu, B., Loparo, Z., Nath, J., Peale, R. E., \& Vasu, S. S. 2015, J. Quant. Spectr. Rad. Transf., 152, 107

Lacy, J., Evans, N. J., Achtermann, J., et al. 1989, ApJ, 342, L43

Lahuis, F., \& Van Dishoeck E. F. 2000, A\&A, 355, 699

Ligterink, N., Calcutt, H., Coutens, A., et al. 2018, A\&A, 619, A28

Linnartz, H., Ioppolo, S., \& Fedoseev, G. 2015, Int. Rev. Phys. Chem., 34, 205

Lykke, J. M., Coutens, A., Jørgensen, J. K., et al. 2017, A\&A, 597, A53

Max, J.-J., Daneault, S., \& Chapados, C. 2002, Can. J. Chem., 80, 113

McGuire, B. A., Carroll, P. B., Loomis, R. A., et al. 2016, Science, 352 aae0328

Moore, M., \& Hudson, R. 1998, Icarus, 135, 518

Moore, M., \& Hudson, R. 2003, Icarus, 161, 486

Moran, L. A., Horton, H. R., Scrimgeour, G., \& Perry, M. 2012, Principles of Biochemistry (Boston: Pearson)

Müller, H. S., Belloche, A., Xu, L.-H., et al. 2016, A\&A, 587, A92

Mumma, M. J., \& Charnley, S. B. 2011, ARA\&A, 49, 471

Öberg, K. I., Boogert, A. A., Pontoppidan, K. M., et al. 2008, ApJ, 678, 1032

Öberg, K. I., Garrod, R. T., Van Dishoeck, E. F., \& Linnartz, H. 2009, A\&A, 504,891

Öberg, K. I., Boogert, A. A., Pontoppidan, K. M., et al. 2011, Proc. IAU Symp. 280,65

Pontoppidan, K. M. 2006, A\&A, 453, L47

Qasim, D., Chuang, K.-J., Fedoseev, G., et al. 2018, A\&A, 612, A83

Rangwala, N., Colgan, S. W., Le Gal, R., et al. 2018, ApJ, 856, 9

Requena-Torres, M., Martín-Pintado, J., Martín, S., \& Morris, M. 2008, ApJ, 672,352

Salyk, C. 2011, Proc. IAU Symp. 280, 127

Song, L., \& Kästner, J. 2017, ApJ, 850, 118

Taquet, V., van Dishoeck, E. F., Swayne, M., et al. 2018, A\&A, 618, A11

Tercero, B., Cernicharo, J., López, A., et al. 2015, A\&A, 582, L1

Tschersich, K. 2000, J. Appl. Phys., 87, 2565

Tschersich, K., \& Von Bonin, V. 1998, J. Appl. Phys., 84, 4065

Tschersich, K., Fleischhauer, J., \& Schuler, H. 2008, J. Appl. Phys., 104, 034908

Watanabe, N., \& Kouchi, A. 2002, ApJ, 571, L173

Watanabe, N., Shiraki, T., \& Kouchi, A. 2003, ApJ, 588, L121

Weigend, F., Häser, M., Patzelt, H., \& Ahlrichs, R. 1998, Chem. Phys. Lett., 294, 143

Woon, D. E. 2002, ApJ, 569, 541

Zaverkin, V., Lamberts, T., Markmeyer, M., \& Kästner, J. 2018, A\&A, 617, A25

Zhao, Y., \& Truhlar, D. G. 2004, J. Phys. Chem. A, 108, 6908

Zhou, L., Kaiser, R. I., Gao, L. G., et al. 2008, ApJ, 686, 1493

Zhou, L., Maity, S., Abplanalp, M., Turner, A., \& Kaiser, R. I. 2014, ApJ, 790, 38 
D. Qasim et al.: Formation of interstellar propanal and 1-propanol ice

Appendix A: Additional RAIR spectra

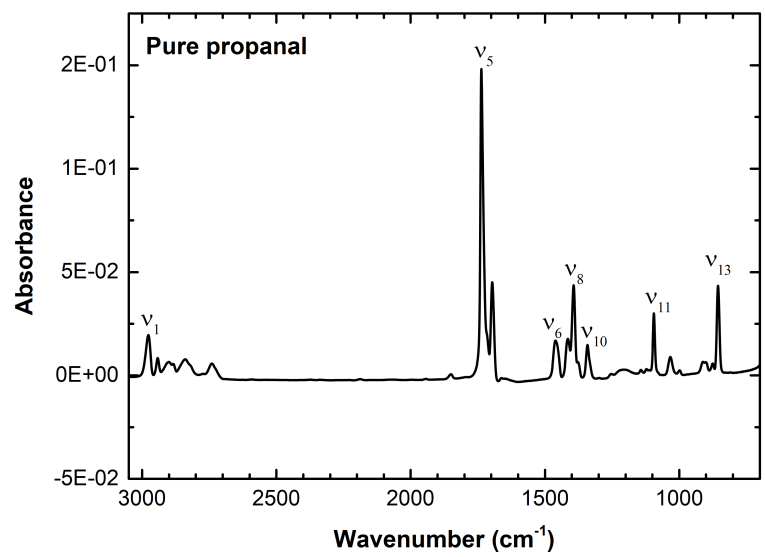

Fig. A.1. RAIR spectrum of propanal (exp. 2.4) taken at $10 \mathrm{~K}$. Vibrational mode assignments are acquired from the work by Köroğlu et al. (2015)

\section{Appendix B: xyz coordinates of the transition state structures for $\mathrm{HCO}+\mathrm{C}_{2} \mathrm{H}_{2}$ and $\mathrm{HCO}+\mathrm{C}_{2} \mathrm{H}_{4}$}

Table B.1. Transition state (TS) geometries for $\mathrm{HCO}+\mathrm{C}_{2} \mathrm{H}_{2}$ and $\mathrm{HCO}+$ $\mathrm{C}_{2} \mathrm{H}_{4}$ in the gas-phase.

\begin{tabular}{cccc}
\hline \hline & \multicolumn{3}{c}{$\mathrm{TS}$} \\
& \multicolumn{3}{c}{$\mathrm{R} 1: \mathrm{HCO}+\mathrm{C}_{2} \mathrm{H}_{2} \rightarrow \mathrm{HCCHCHO}$} \\
$\mathrm{C}$ & 2.457338 & 0.140746 & 0.005500 \\
$\mathrm{C}$ & 2.631181 & -0.091562 & 1.180635 \\
$\mathrm{H}$ & 2.643330 & -0.284788 & 2.221672 \\
$\mathrm{H}$ & 2.726948 & 0.284977 & -1.012337 \\
$\mathrm{H}$ & -0.004679 & 0.618071 & 0.718368 \\
$\mathrm{C}$ & 0.378597 & 0.141577 & -0.202373 \\
$\mathrm{O}$ & -0.111318 & -0.735052 & -0.794637 \\
\hline & \multicolumn{3}{c}{$\mathrm{R} 2: \mathrm{HCO}+\mathrm{C}_{2} \mathrm{H}_{4} \rightarrow \mathrm{H}_{2} \mathrm{CCH}_{2} \mathrm{CHO}$} \\
$\mathrm{C}$ & 2.503771 & 0.131055 & -0.104025 \\
$\mathrm{C}$ & 2.587871 & -0.106220 & 1.216301 \\
$\mathrm{H}$ & 2.638529 & 0.697532 & 1.930552 \\
$\mathrm{H}$ & 2.561540 & -1.108352 & 1.607866 \\
$\mathrm{H}$ & 2.634615 & 1.125558 & -0.495603 \\
$\mathrm{H}$ & 2.576039 & -0.671720 & -0.817177 \\
$\mathrm{H}$ & 0.014387 & 0.814221 & 0.535546 \\
$\mathrm{C}$ & 0.362966 & 0.096368 & -0.230237 \\
$\mathrm{O}$ & -0.158186 & -0.904331 & -0.528368 \\
\hline
\end{tabular}

Appendix C: 1-propanol spectra at $T_{\mathrm{ex}}=125$ and $300 \mathrm{~K}$
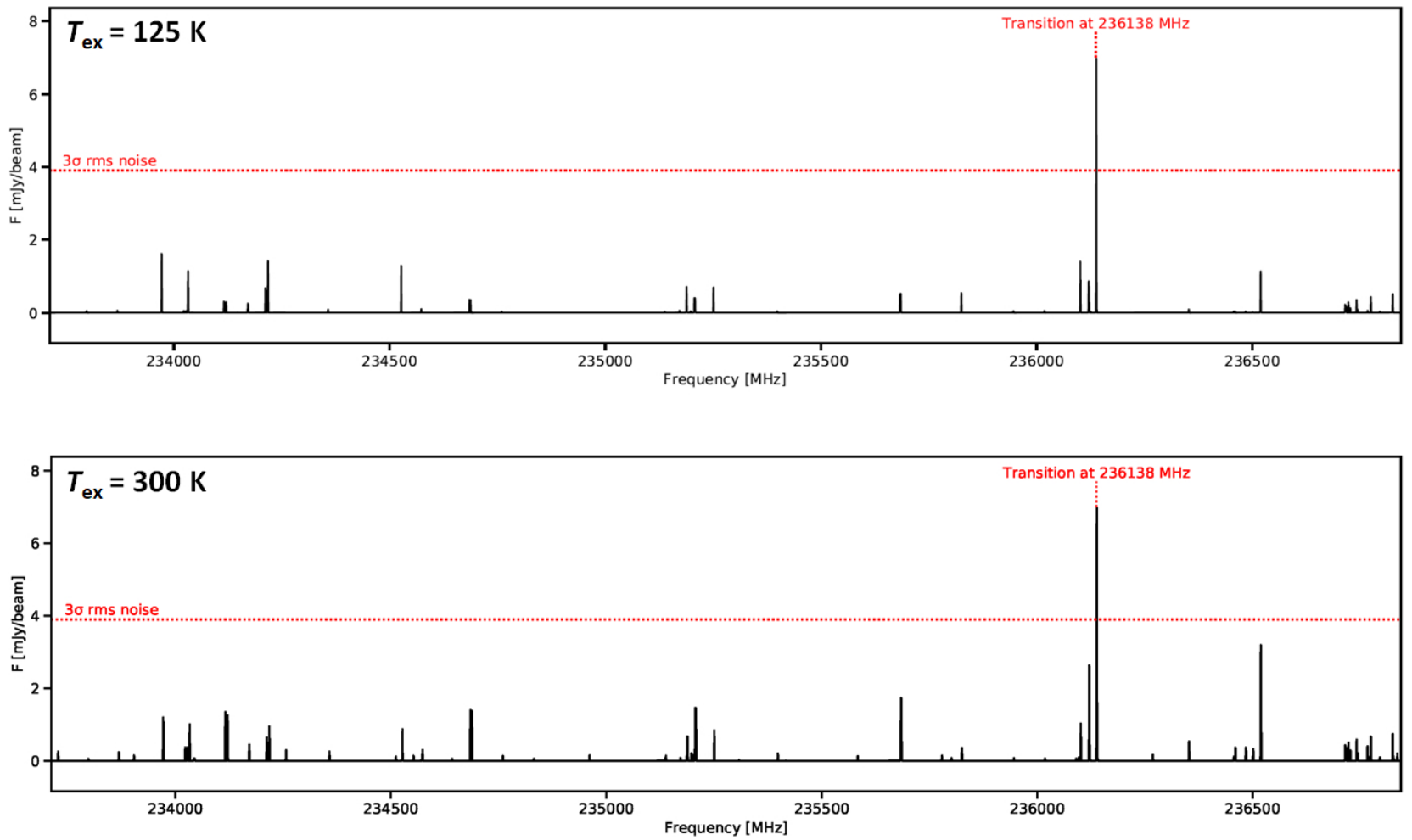

Fig. C.1. Synthetic spectra of the 1-propanol emission for excitation temperatures $T_{\mathrm{ex}}=125 \mathrm{~K}$ (top) and $300 \mathrm{~K}$ (bottom) with associated 1-propanol column densities of $7.6 \times 10^{14} \mathrm{~cm}^{-2}$ and $1.2 \times 10^{15} \mathrm{~cm}^{-2}$, respectively. These are the highest column densities that result in non-detection of the 1 -propanol transition at $236.138 \mathrm{GHz}$ (see text for more details). 